\title{
Catalase-like nanosystem for interlocking trimodal cancer therapy with hypoxia relief
}

\author{
Liyao Luo ${ }^{\dagger}$, Lei $\mathrm{Li}^{\dagger}$, Cong Cong, Yaqian He, Zining Hao and Dawei Gao*
}

\begin{abstract}
Hypoxia is a hallmark of solid tumors, and it significantly impairs the overall anticancer efficacy, particularly photodynamic therapy (PDT). Herein, a catalase-like nanovesicle with near-infrared light-responsiveness, that is, platinum/gold nanoshell encapsulated chlorin e6 (Ce6)/resveratrol (Res) liposome (Pt@Au-Ce6/Res-Lip), was developed to surmount this intractable issue. The Pt@Au-Ce6/Res-Lip can decompose overexpressed $\mathrm{H}_{2} \mathrm{O}_{2}$ in tumor microenvironment to produce vast amounts of $\mathrm{O}_{2}$ for further enhancement of the PDT. Under the $808 \mathrm{~nm}$ laser irradiation, the Au nanoshells induced hyperthermia at the lesion site to ablate tumor cells, simultaneously inducing the controlled release of photosensitizer Ce6 and chemotherapeutic agent Res. Moreover, stimulated by $660 \mathrm{~nm}$ laser, numerous reactive oxygen species were formed to induce apoptosis and necrosis of tumor cells. With the cascade of trimodal therapeutic modality options (chemotherapy, photothermal therapy, and PDT), the Pt@Au-Ce6/Res-Lip showed ultrahigh tumor inhabitation rate in in vitro and in vivo studies, signifying that the Pt@AuCe6/Res-Lip nanovesicle is a promising candidate for effective cancer therapy.
\end{abstract}

Keywords: hypoxia, enhanced photodynamic therapy, catalaselike, hyperthermia, trimodal therapeutic modality

\section{INTRODUCTION}

Photodynamic therapy (PDT) has been considered as a promising therapeutic modality option with excellent controllability, high selectivity, and minimal invasiveness for tumor therapy [1,2]. During the PDT process, molecular oxygen plays an essential role in the photoactivated generation of reactive singlet oxygen, which can induce the apoptosis and necrosis of tumor cells [3]. However, the performance of PDT is severely attenuated by tumor hypoxia, which is caused by the imbalance between the consumption and supply of $\mathrm{O}_{2}$ in tumor tissues due to the aberrant neoplastic cell proliferation and distorted tumor vasculatures $[4,5]$. The $\mathrm{O}_{2}$ concentrations vary with the locations of solid tumors, with several interior regions having very low levels (partial pressure of $\mathrm{O}_{2}<5 \mathrm{mmHg}$, corresponding to $7 \mu \mathrm{mol} \mathrm{L}^{-1}$ ), resulting in the low therapeutic efficiency of PDT in deep tumor tissues [6,7]. The vascular damage by PDT and oxygen consumption during this procedure will further worsen the $\mathrm{O}_{2}$ shortage and inevitably exacerbate tumor hypoxic stress [8]. Consequently, advanced strategies are needed to address the negative consequences of hypoxia and improve the clinical application of PDT.

Various innovative methods have been explored to overcome the hypoxia in tumor microenvironment (TME). Considerable research efforts have been focused on directly transporting $\mathrm{O}_{2}$ to tumors with appropriate $\mathrm{O}_{2}$ carriers, such as hemoglobin and perfluorocarbons, or improving the blood flow to increase $\mathrm{O}_{2}$ concentrations in tumors [7,9-11]. Nevertheless, significant problems, including insufficient $\mathrm{O}_{2}$ supply, poor $\mathrm{O}_{2}$ loading, rapid $\mathrm{O}_{2}$ leakage, and difficult co-delivery with desired therapeutics, limit the wide application of these methods $[2,12,13]$. Given the elevated $\mathrm{H}_{2} \mathrm{O}_{2}$ levels (50-100 $\mu \mathrm{mol} \mathrm{L}^{-1}$ ) of the TME, the decomposition of intratumoral $\mathrm{H}_{2} \mathrm{O}_{2}$ to generate $\mathrm{O}_{2}$ in situ with catalase (a kind of bio-enzyme) has attracted extensive research interest [14,15]. However, as an exogenous protein, difficulties in storage, immunogenicity, and protease-induced degradation in delivery process limit the application of catalase in complicated physiological environments [16]. Based on the catalytic performance of natural enzymes, a variety of synthetic structures have been engineered to mimic the functions and complexities of natural enzymes over the past several decades $[17,18]$. Pt catalysts have

State Key Laboratory of Metastable Materials Science and Technology, Applying Chemistry Key Lab of Hebei Province, Heavy metal deepremediation in water and resource reuse Key Lab of Hebei, Yanshan University, Qinhuangdao 066004, China

These two authors contributed equally to this work.

* Corresponding author (email: dwgao@ysu.edu.cn) 
been extensively studied due to their superior performance as heterogeneous catalysts in numerous processes. For instance, Pt-based nanostructures exhibit high catalytic activity toward methanol oxidation $[19,20]$. Especially, Qin and co-workers [21] have recently identified that $\mathrm{Pt}$ is considerably more active and stable during the catalytic decomposition of $\mathrm{H}_{2} \mathrm{O}_{2}$ than catalase. However, most of these studies are included in the field of chemistry. Pt-based structures have shown great promise for use as therapeutics for neurodegenerative diseases and cancers [22]. If the $\mathrm{Pt}$ component can serve as an inorganic nanoenzyme to convert tumor-abundant $\mathrm{H}_{2} \mathrm{O}_{2}$ molecules into $\mathrm{O}_{2}$ under physiological conditions, the application prospects for facilitating PDT-induced reactive oxygen species (ROS) generation can be achieved and used to subsequently enhance the PDT efficacy.

Photothermal therapy (PTT) is another effective phototherapy that can convert light energy into heat through photothermal agents to ablate cancer cells with minimally invasive damage to normal tissues [23]. In the process, incident light is one of the vital factors. As near-infrared
(NIR) light can penetrate the tissues with minimal energy loss and reach the diseased region, it is adopted widely to stimulate PTT [24]. In addition, Au nanomaterials are state-of-the-art efficient photothermal agents that exhibit the superior capability of photothermal conversion in PTT with the unique optical property of surface plasmon resonance in the NIR region and good biocompatibility [25]. According to our previous report, with its excellent photothermal effect, the combination of $\mathrm{Au}$ nanostructures and drug delivery carriers can activate the controllable drug release and realize PTT and chemotherapy (CHT) in one nanoplatform [26]. Thus, Au nanomaterials show a broad prospect in the field of cancer treatment.

Herein, we engineered a versatile nanovesicle, that is, platinum/gold nanoshell encapsulated chlorin e6 (Ce6)/ resveratrol (Res) liposome (Pt@Au-Ce6/Res-Lip), with Pt and $\mathrm{Au}$ decorated on the surface of liposome-encapsulated photosensitizers, namely, Ce6 and Res, for trimodal cancer therapy against hypoxic tumor (Scheme 1). Res, a polyphenol compound extracted from

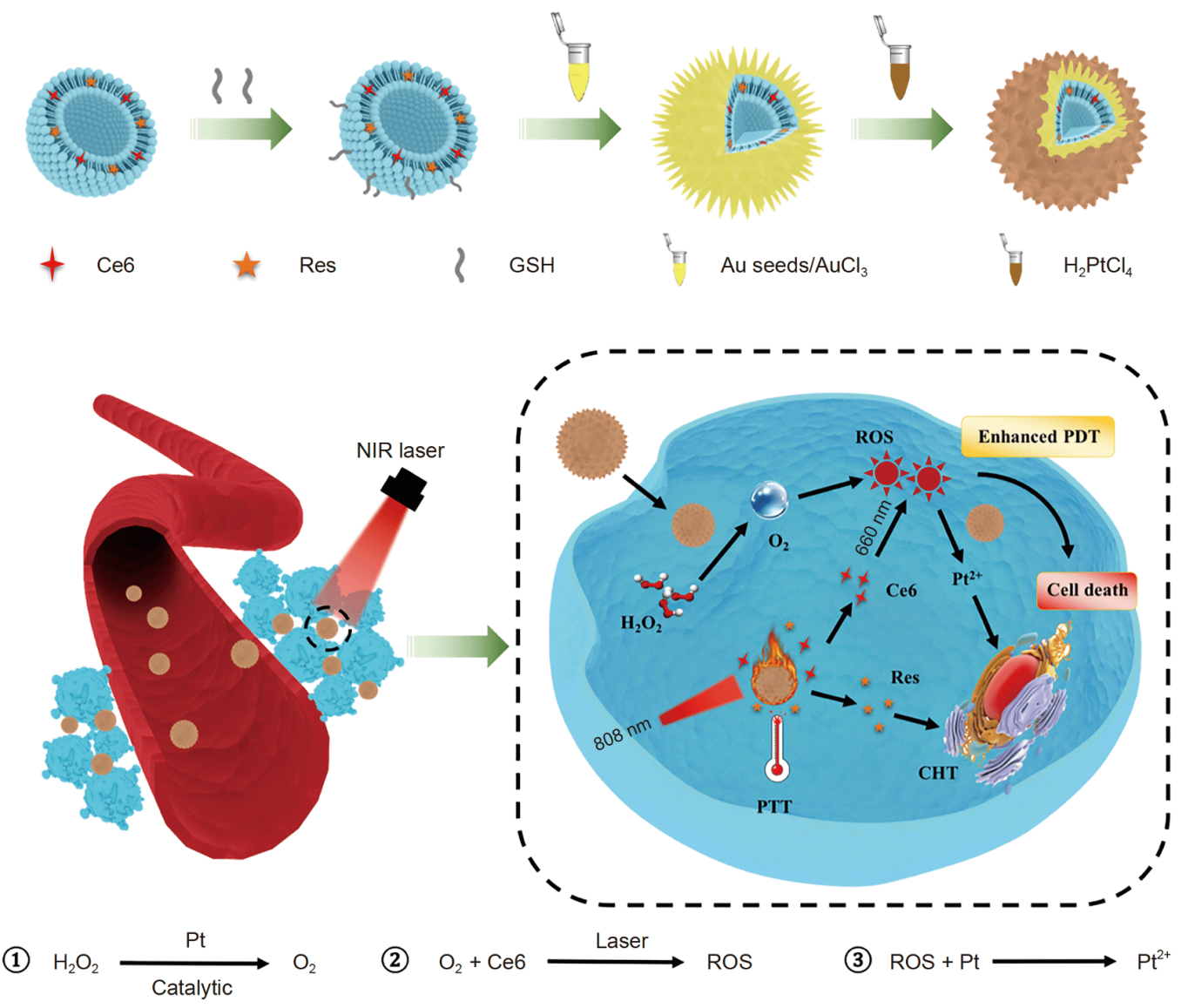

Scheme 1 Schematic of Pt@Au-Ce6/Res-Lip preparation and the functional mechanism for the synergistic trimodal cancer therapy with hypoxia relief. 
many plants, possesses excellent antitumor property [27]. When the nanovesicles reach the hypoxic tumor, the Pt component in Pt@Au-Ce6/Res-Lip can boost the formation of $\mathrm{O}_{2}$ in the tumor site via endogenous $\mathrm{H}_{2} \mathrm{O}_{2}$ evolvement, which can be used for further PDT. Simultaneously, with the plasma resonance effect of the Pt@Au nanoshell, the nanocarriers can rapidly convert NIR light into heat to accelerate the controllable release of Ce6 and Res under an $808 \mathrm{~nm}$ laser. Followed by the $660 \mathrm{~nm}$ laser irradiation, Ce6 was excited to transfer energy and produce massive amounts of ROS to cause irreversible cell damage. Meanwhile, high concentration of ROS in the TME oxidized $\mathrm{Pt}^{0}$ into $\mathrm{Pt}^{2+}$ ions, which have better penetration of nuclear membrane than PtNPs, to realize the high cytotoxicity toward tumor cells. As evidenced by the antitumor study in vitro and in vivo, the Pt@Au-Ce6/Res-Lips demonstrated an ultrahigh tumor inhibition rate with the combination of trimodal therapeutic modality options, including PDT, PTT, and CHT. Our findings will open an avenue for Pt nanomaterials as efficient agents toward biological applications.

\section{EXPERIMENTAL SECTION}

\section{Synthesis of glutathione (GSH)-Ce6/Res-Lips}

A facile ethanol injection method was used for the synthesis of liposomes co-loaded with Ce6 and Res. First, the lipid phase was obtained by dissolving cholesterol $(6 \mathrm{mg})$ and soya lecithin $(50 \mathrm{mg})$ in $4 \mathrm{~mL}$ ethyl alcohol, followed by ultrasonic dispersion of Ce6 (1 mg) and Res $(2 \mathrm{mg}$ ). Then, $10 \mathrm{~mL}$ aqueous solution containing $10 \mu \mathrm{L}$ Tween- 80 and $0.5 \mathrm{~mL}$ phosphate buffer was heated to a mild temperature $\left(43^{\circ} \mathrm{C}\right)$. Subsequently, the lipid phase was added dropwise to the above aqueous solution, and the mixture was stirred at room temperature for $1 \mathrm{~h}$ to volatilize the ethyl alcohol adequately. Afterward, GSH solution $\left(7 \mathrm{mg} \mathrm{mL}^{-1}\right)$ was added to the above mixture with continuous stirring for $2 \mathrm{~h}$ to obtain GSH-Ce6/ResLip, which was further purified by dialysis to remove free Res and Ce6.

\section{Synthesis of AuNF-Ce6/Res-Lips}

Gold nanoflakes (AuNF)-Ce6/Res-Lips were prepared by using our previously reported method [28]. First, Au seeds were acquired by reducing auric chloride $\left(\mathrm{AuCl}_{3}\right)$ with fresh $\mathrm{NaBH}_{4}$ in the aqueous phase. Then, the $\mathrm{Au}$ seeds were added to the GSH-Ce6/Res-Lips at the volume ratio of $1: 1$ and reacted for $20 \mathrm{~h}$. Subsequently, a growth solution including $2 \mathrm{mmol} \mathrm{L}^{-1} \mathrm{AuCl}_{3}(500 \mu \mathrm{L})$ diluted by $\mathrm{K}_{2} \mathrm{CO}_{3}$ solution $\left(1.5 \mathrm{mg} \mathrm{mL}^{-1}\right)$ and $100 \mathrm{mmol} \mathrm{L}^{-1}$ fresh hydroxylamine hydrochloride $(50 \mu \mathrm{L})$ was added to the above product for further incubation $(8 \mathrm{~h})$ at room temperature. The mixture finally exhibited glaucous color, suggesting the formation of AuNF-Ce6/Res-Lips.

\section{Synthesis of Pt@Au-Ce6/Res-Lips}

The obtained AuNF-Ce6/Res-Lips were further mixed with $1 \mathrm{mmol} \mathrm{L}^{-1} \mathrm{H}_{2} \mathrm{PtCl}_{4}(300 \mu \mathrm{L})$ and $60 \mathrm{mmol} \mathrm{L}^{-1}$ ascorbic acid $(40 \mu \mathrm{L})$ to grow Pt shells on the surface of AuNF-Ce6/Res-Lips. The process lasted for $10 \mathrm{~h}$ at room temperature. An evident color change of the solution from glaucous to dark gray indicated the acquisition of Pt@Au-Ce6/Res-Lips. Afterward, a purified Pt@Au-Ce6/ Res-Lip solution was collected by centrifugation at the speed of $8000 \mathrm{rpm}$ for $15 \mathrm{~min}$. The encapsulation efficacy (EE\%) of Ce6 or Res was calculated using the formula $\mathrm{EE} \%=W_{\mathrm{e}} / W_{\mathrm{t}} \times 100 \%$, where $W_{\mathrm{e}}$ is the amount of encapsulated drug, and $W_{\mathrm{t}}$ is the initial amount of the drug added in the preparation.

\section{Light-induced photothermal performance and drug release}

Briefly, the Pt@Au-Ce6/Res-Lip solutions with different $\mathrm{Au}$ concentrations were placed in a quartz cuvette and exposed to an $808 \mathrm{~nm}$ laser with a different power density for $10 \mathrm{~min}$. Then, the temperature changes were monitored using an IR thermal imaging camera at the selected time intervals ( $1 \mathrm{~min}$ ). The AuNF-Ce6/Res-Lips and $\mathrm{H}_{2} \mathrm{O}$ were used as controls. The NIR-responsive release behavior of Res from the Pt@Au-Ce6/Res-Lips was investigated with or without $808 \mathrm{~nm}$ laser irradiation using a dialysis method. First, $1 \mathrm{~mL}$ Pt@Au-Ce6/Res-Lips was placed in dialysis bags $(3500 \mathrm{D})$ and then maintained at $37^{\circ} \mathrm{C}$ in a phosphate-buffered saline (PBS) (pH 7.4) solution bath with constant stirring. Then, at 1,4 , and $8 \mathrm{~h}$, the samples in the laser group were exposed to the $808 \mathrm{~nm}$ laser $\left(1.5 \mathrm{~W} \mathrm{~cm}^{-2}\right)$ for $3 \mathrm{~min}$. At the designated time points $(1,2,4,8$, and $12 \mathrm{~h})$, the samples with or without $808 \mathrm{~nm}$ laser irradiation were retrieved for measurement of the absorbance at $306 \mathrm{~nm}$ using an ultraviolet-visible (UV-vis) spectrophotometer.

\section{Catalase activity detection of Pt@Au-Ce6/Res-Lips}

To confirm the catalase activity of nanoparticles (NPs), we used Pt@Au-Lips to replace Pt@Au-Ce6/Res-Lips to avoid the influence of absorption of Ce6. A total of $100 \mu \mathrm{L}$ $3,3^{\prime}, 5,5^{\prime}$-tetramethyl-benzidine (TMB) $\left(10 \mathrm{mmol} \mathrm{L}^{-1}\right)$ was applied to monitor the chromogenic reaction $(\lambda=$ $652 \mathrm{~nm}$ ) of $1 \mathrm{~mL}$ of aqueous solution containing $\mathrm{H}_{2} \mathrm{O}_{2}$ $\left(0.1 \mathrm{mmol} \mathrm{L}^{-1}\right)$ and Pt@Au-Lips with different Pt con- 
centrations $\left(0,10,25\right.$, and $\left.50 \mu \mathrm{g} \mathrm{mL}^{-1}\right)$. After $5 \mathrm{~min}$, the absorbance of the mixture at $652 \mathrm{~nm}$ was measured with a UV-vis spectrophotometer. The color changes of the solutions were recorded using an imaging camera.

Different Pt concentrations $\left(0,10,25\right.$, and $\left.50 \mu \mathrm{g} \mathrm{mL} \mathrm{L}^{-1}\right)$ of Pt@Au-Ce6/Res-Lips were dispersed in deoxygenated PBS solution containing $0.1 \mathrm{mmol} \mathrm{L}^{-1} \mathrm{H}_{2} \mathrm{O}_{2}$ to detect the $\mathrm{O}_{2}$ production. A dissolved $\mathrm{O}_{2}$ meter (Shanghai Ray magnetic JPBJ-608) was inserted into the above solution to measure the $\mathrm{O}_{2}$ content at different time points. Meanwhile, the bubble production of the solutions was recorded using a camera.

\section{Detection of reactive singlet oxygen}

1,3-Diphenylisobenzofuran (DPBF), a commercially available luminescent probe for ROS detection, was used to detect the ROS generation. Briefly, $50 \mu \mathrm{L}$ DPBF solution $\left(1 \mathrm{mg} \mathrm{mL}^{-1}\right)$ was introduced to the samples of AuNF-Ce6/Res-Lips and Pt@Au-Ce6/Res-Lips with equal Ce6 content. Subsequently, the mixtures were deoxygenated with pure nitrogen stream for $30 \mathrm{~min}$. Afterward, $\mathrm{H}_{2} \mathrm{O}_{2}\left(0.1 \mathrm{mmol} \mathrm{L}^{-1}\right)$ was added to the above solutions, and the mixtures were pre-irradiated by $808 \mathrm{~nm}$ laser for $3 \mathrm{~min}$. After keeping in the dark place for $30 \mathrm{~min}$, the above solutions were exposed to a $660 \mathrm{~nm}$ laser $\left(0.15 \mathrm{~W} \mathrm{~cm}^{-2}\right)$ for different periods, and the UV-vis absorption spectrum of DPBF at $410 \mathrm{~nm}$ was measured to evaluate the generation of ROS. Additionally, X-ray photoelectron spectroscopy (XPS) was conducted to characterize the oxidization statues of Pt before and after the ROS generation in the simulated TME.

The intracellular ROS content was measured with 2,7dichlorodihydrofluorescein (DCFH) as a probe. Hela cells were seeded into a six-well plate with an initial cell density of $10^{4}$ cells $\mathrm{cm}^{-2}$. When the cell confluency reached about $80 \%$, the original culture medium was discarded and replaced by a fresh one containing PBS (control), $10 \mu \mathrm{g} \mathrm{mL}{ }^{-1}$ equivalent concentration (Ce6) of free Ce6, AuNF-Ce6-Lips, and Pt@Au-Ce6-Lips separately. Simultaneously, exogenous $\mathrm{H}_{2} \mathrm{O}_{2}\left(0.1 \mathrm{mmol} \mathrm{L}^{-1}\right)$ was added to all the groups. After incubation for $4 \mathrm{~h}$, the AuNF-Ce6-Lip and Pt@Au-Ce6-Lip groups were irradiated with an $808 \mathrm{~nm}$ laser $\left(1.5 \mathrm{~W} \mathrm{~cm}^{-2}\right)$ for $3 \mathrm{~min}$. Afterward, the cells were washed thrice with serum-free medium and dyed with DCFH-diacetate (DA) at $37^{\circ} \mathrm{C}$ for $20 \mathrm{~min}$. Then, all the groups were exposed to $660 \mathrm{~nm}$ laser $\left(0.15 \mathrm{~W} \mathrm{~cm}^{-2}\right)$ for $3 \mathrm{~min}$ and further incubated for $20 \mathrm{~min}$. The 2,7-dichlorofluorescein (DCF) fluorescence intensity of the cells was eventually measured with a fluorescence microscope (MSHOT MF53).

\section{Cellular uptake and in vitro combined antitumor therapy} assay

The internalization of the NPs was evaluated using fluorescence microscopy (MSHOT MF53) and flow cytometry (FCM, BD FACSCalibur, USA). Coumarin-6 (Cou6) with a fluorescent green signal was encapsulated in the liposomes to trace the location of the NPs in cells. Pt@Au-Cou6-Lips were obtained by replacing Ce6 and Res with Cou6 (1 mg) during the preparation of Pt@AuCe6/Res-Lips. First, HeLa cells were seeded in six-well plates at a density of $3 \times 10^{5}$ cells per well and cultured to $80 \%$ confluency. Then, the culture medium was replaced by Pt@Au-Cou6-Lips $\left(2.5 \mu \mathrm{g} \mathrm{mL} \mathrm{m}^{-1}\right.$ Cou6) suspended in fresh medium, and the culturing was continued for 1,2 , 4 , and $8 \mathrm{~h}$. After the above treatment, the cells were adequately rinsed with PBS to remove the residual free NPs. Subsequently, the cell nuclei were stained with Hoechst for $8 \mathrm{~min}$ and then observed by fluorescence microscope. The quantitative analysis of intracellular Pt@Au-Cou6-Lips was carried out with FCM at different time points.

The cytotoxicity of Pt@Au-Ce6/Res-Lips was analyzed utilizing the standard 3-(4,5-dimethylthiazol-2-yl)-2,5diphenyl tetrazolium bromide (MTT) assay. In brief, the HeLa cells were planted in 96-well microplates at $10^{4}$ cells per well and allowed to adhere overnight. Then, the culture medium was replaced by $200 \mu \mathrm{L}$ opti-Dulbecco's Modified Eagle Medium (DMEM) containing different formulations (free Res, AuNF-Ce6/Res-Lips, and Pt@AuCe6/Res-Lips) with gradient concentrations of Res, with PBS group as the control group. After additional incubation for $4 \mathrm{~h}$, the cells were irradiated by $808 \mathrm{~nm}$ laser $\left(1.5 \mathrm{~W} \mathrm{~cm}^{-2}\right)$ for $3 \mathrm{~min}$ and $660 \mathrm{~nm}$ laser $\left(0.15 \mathrm{~W} \mathrm{~cm}^{-2}\right)$ for $4 \mathrm{~min}$. Subsequently, the medium was replaced by $200 \mu \mathrm{L}$ MTT solution $\left(5 \mathrm{mg} \mathrm{mL}^{-1}\right.$ in DMEM) and further incubated for $4 \mathrm{~h}$. Afterward, MTT was replaced by $150 \mu \mathrm{L}$ dimethyl sulfoxide. A microplate reader was used to explore the cell viability by recording the absorbance at a wavelength of $490 \mathrm{~nm}$. Hypoxia conditions were established in accordance with the method previously reported by $\mathrm{Yu}$ et al. [2] to analyze the enhanced photodynamic effect of Pt@Au-Ce6-Lips compared with AuNF-Ce6-Lips; the cells were cultured in deoxidation DMEM, and the oxygen supply was severed by sealing the culture medium with liquid paraffin. The photodynamic effects of free Ce6 and Pt@Au-Ce6/Res-Lips under $660 \mathrm{~nm}$ laser irradiation in normoxic and hypoxic conditions were also studied. Other treatments were performed similarly as above. The cytotoxicity of different formulations was also evaluated with the standard pro- 
tocol of fluorescence staining of live/dead cells by two probes, namely, 3,6-diacetoxyfluoran (FDA) and propidium iodide (PI) [29].

\section{In vivo cancer therapeutic efficacy and biosafety assay} All animal operations were performed in agreement with the Statute of Experimental Animal Ethics Committee of Department of Bioengineering by Yanshan University. Female Kunming mice, 6-8 weeks of age, were purchased from Vitalriver Laboratory Animal Center. Then, $2 \times 10^{6}$ U14 tumor cells were subcutaneously implanted into the posterior limb of the mice to establish the in vivo tumor model. When the size of the tumor reached around $100 \mathrm{~mm}^{3}$, the mice were used for the following experiments.

A total of $200 \mu \mathrm{L}$ Pt@Au-Ce6/Res-Lips were intratumorally injected into the mice to investigate the PTT of Pt@Au-Ce6/Res-Lips in vivo. Meanwhile, an equal amount of saline was injected as control. Subsequently, the tumor regions were irradiated with the $808 \mathrm{~nm}$ laser $\left(1.5 \mathrm{~W} \mathrm{~cm}^{-2}\right)$ for $5 \mathrm{~min}$. The tumor temperature changes were monitored using an IR thermal imaging camera.

To evaluate the in vivo antitumor efficacy of Pt@AuCe6/Res-Lips, we divided randomly the tumor-bearing mice into eight therapy groups ( $n=6$ per group) and performed the following treatments: Group 1, saline; Group 2, Res-Lips; Group 3, Ce6-Lips; Group 4, Pt@AuLips with $808 \mathrm{~nm}$ laser irradiation; Group 5, AuNF-Ce6Lips with 808/660 nm laser irradiation; Group 6, Pt@AuCe6-Lips with 808/660 nm laser irradiation; Group 7, Pt@Au-Ce6/Res-Lips; Group 8, Pt@Au-Ce6/Res-Lips with $808 / 660 \mathrm{~nm}$ laser irradiation. Each group was intratumorally injected with the samples containing Res $\left(1.0 \mathrm{mg} \mathrm{kg}^{-1}\right)$ and Ce6 $\left(0.21 \mathrm{mg} \mathrm{kg}^{-1}\right)$. At $4 \mathrm{~h}$ postinjection, the tumor areas were irradiated with an $808 \mathrm{~nm}$ laser $\left(1.5 \mathrm{~W} \mathrm{~cm}^{-2}\right)$ for $3 \mathrm{~min}$. At $30 \mathrm{~min}$ intervals, the $660 \mathrm{~nm}$ laser $\left(0.15 \mathrm{~W} \mathrm{~cm}^{-2}\right)$ irradiation was performed for $3 \mathrm{~min}$. The tumor sizes and weights of mice were measured every other day. Tumor volume $=$ width $\times$ width $\times$ length/2. After 15 days, all tumor-bearing mice were sacrificed, and the primary organs (heart, liver, spleen, lung, and kidney) and tumor tissues were excised for hematoxylin-eosin (H\&E) staining. For biochemical index analysis, blood was collected from the eye socket to examine the serum biochemical parameters, including aspartate aminotransferase (AST), alanine aminotransferase (ALT), and blood urea nitrogen (BUN). Meanwhile, the expression levels of hypoxia inducible factor-1a (HIF-1a), vascular endothelial growth factor (VEGF), erythropoietin (EPO), glucose transporters (GLUT3,) and multidrug resistance (MDR1) were checked with an enzyme-linked immunosorbent assay kit to evaluate the tumor hypoxia relief. The tumor tissue homogenate was used, and the specific procedures are provided in the Supplementary information.

\section{Statistical analysis}

Quantitative data were shown as a mean value with its standard deviation (mean $\pm \mathrm{SD}$ ). Statistical significance $\left({ }^{*} P<0.05\right.$ or $\left.{ }^{* *} P<0.01\right)$ was determined by using oneway analysis of variance with SPSS 19.0 for Windows (SPSS Inc., Chicago, IL, USA).

\section{RESULTS AND DISCUSSION}

\section{Characterization}

Scheme 1 presents the synthetic process of Pt@Au-Ce6/ Res-Lip nanoplatform. First, Ce6 and Res were co-encapsulated in the liposomes with the ethanol injection method, and the EEs of Ce6 and Res were $49.41 \%$ and $65.27 \%$, respectively. Then, the branched Au nanoshells were connected to the surface of liposomes through the $\mathrm{Au}$ seed growth method to obtain AuNF-Ce6/Res-Lips. Finally, by introducing $\mathrm{H}_{2} \mathrm{PtCl}_{4}$, the PtNPs were successfully combined with AuNF-Ce6/Res-Lips to form Pt@Au-Ce6/res-Lip nanovesicles. As shown by the transmission electron microscopy (TEM) images in Fig. 1a and b, the Pt@Au-Ce6/Res-Lips had an average diameter of $120 \mathrm{~nm}$, which was consistent with the hydrodynamic diameter measured by dynamic light scattering. The appropriate size of the NPs offered well passive target to the tumor site via the enhanced permeability and retention effect [28]. Subsequently, energydispersive X-ray spectroscopy (EDS) manifested that the Pt@Au-Ce6/Res-Lips were composed of Pt and Au, and the ratio of $\mathrm{Pt}$ and $\mathrm{Au}$ was 1:6.1. (Fig. 1c). The distribution of $\mathrm{Au}$ and $\mathrm{Pt}$ can be observed in Fig. S1, which visually shows the shell structure of the NPs. The optical property of Pt@Au-Ce6/Res-Lips was investigated by UV-vis absorption and emission spectra (Fig. 1d). Given the plasma resonance effects of Pt and Au, the Pt@AuCe6/Res-Lips exhibited broad absorption in the NIR region ranging from $600 \mathrm{~nm}$ to $900 \mathrm{~nm}$, providing the possibility to convert NIR light energy into heat energy and conduct thermal therapy [30]. Meanwhile, the characteristic absorption peaks of Ce6 at 410 and $660 \mathrm{~nm}$ appeared in the spectrum of Pt@Au-Ce6/Res-Lips, which indicates that $\mathrm{Ce} 6$ was successfully loaded onto the nanocarriers. Moreover, the storage stability of Pt@Au-Ce6/ Res-Lips at $4^{\circ} \mathrm{C}$ was investigated by measuring the par- 

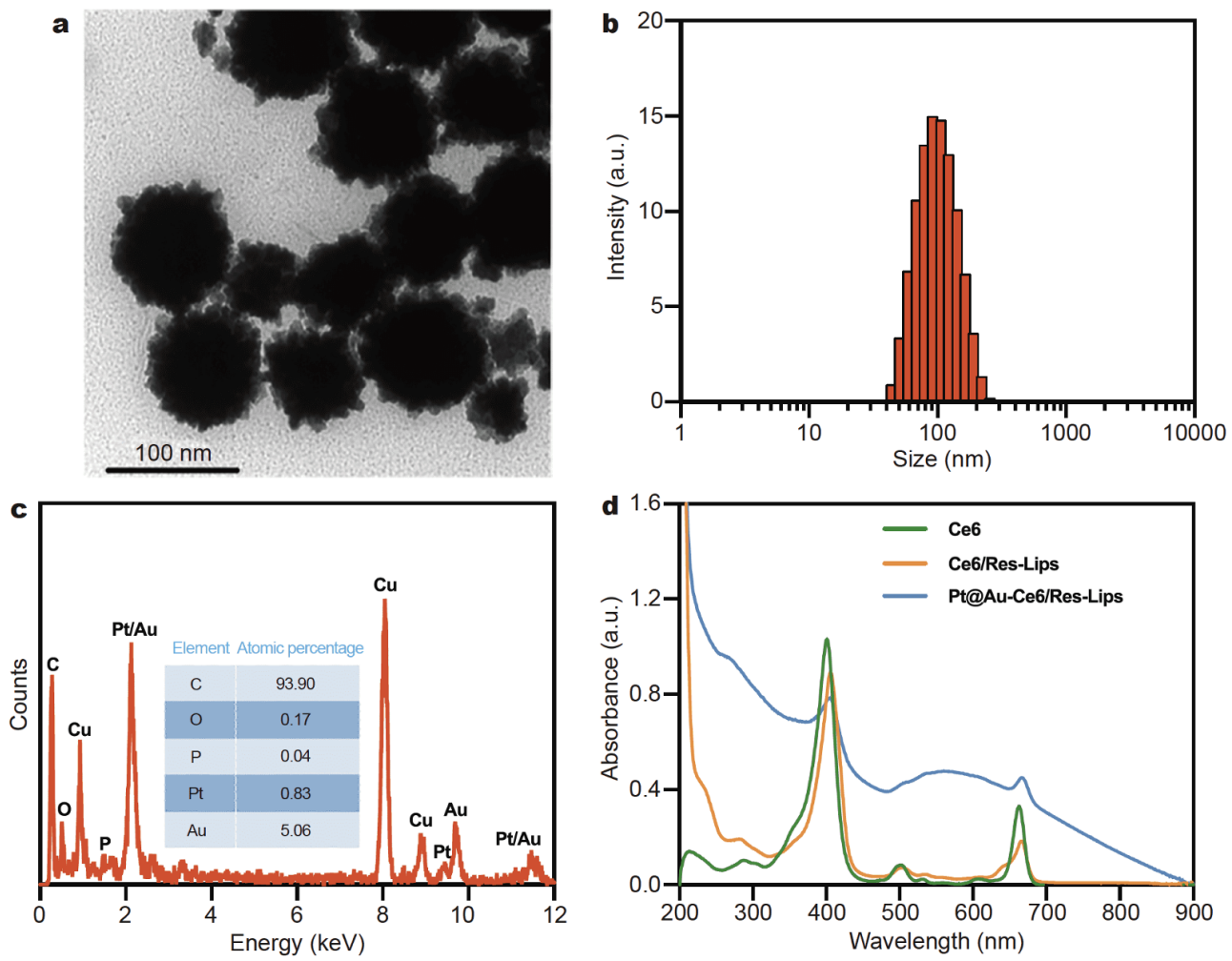

Figure 1 Characterizations of Pt@Au-Ce6/Res-Lips. (a) TEM image; (b) size distribution; (c) EDS analysis of Pt@Au-Ce6/Res-Lips (illustration: atomic percentage of the elements); (d) UV-vis absorbance spectra of Ce6, Ce6/Res-Lips, and Pt@Au-Ce6/Res-Lips.

ticle size changes in a month. No significant change in particle size was observed in one month, indicating the good stability of Pt@Au-Ce6/Res-Lips at $4^{\circ} \mathrm{C}$ (Fig. S2).

\section{Light-induced photothermal performance and drug release}

The capability of Pt@Au-Ce6/Res-Lips as photothermal generators was explored by detecting temperature changes under an $808 \mathrm{~nm}$ NIR laser. As displayed in Fig. 2a, the temperatures of AuNF-Ce6/Res-Lip and Pt@Au-Ce6/ Res-Lip solutions increased rapidly to 57.5 and $68.5^{\circ} \mathrm{C}$ when irradiated with the $808 \mathrm{~nm}$ laser $\left(2 \mathrm{~W} \mathrm{~cm}^{-2}\right)$ for $10 \mathrm{~min}$, respectively. Comparatively, the water showed minimal temperature change under the same condition. The Pt@Au-Ce6/Res-Lips showed a rising temperature with the increase in laser power intensity, exhibiting a laser intensity-dependent behavior (Fig. 2b). Particularly, the temperature of Pt@Au-Ce6/Res-Lips can increase by $26^{\circ} \mathrm{C}$ in 3 min under $2 \mathrm{~W} \mathrm{~cm}^{-2}$. An IR thermal imaging camera recorded the temperature change process of nanovesicles (Fig. 2c), and the findings were consistent with the above results. To our knowledge, the local low heat $\left(\leq 43^{\circ} \mathrm{C}\right)$ can enhance cell membrane fluidity, which fa- cilitates cellular uptake and destroys the endosomal membrane to promote endosomal escape [31]. Thus, the Pt@Au-Ce6/Res-Lips can be used as superior photothermal agents for cancer therapy.

The controllable release behavior of Pt@Au-Ce6/ResLips was further demonstrated (Fig. 2d). Under the $808 \mathrm{~nm}$ laser irradiation, the nanovesicles collapsed and released considerable amount of Res (24.9\%) within $1 \mathrm{~h}$. After three cycles of laser irradiation, the released amount of Res reached up to $75.1 \%$ within $12 \mathrm{~h}$. Without laser irradiation, $28.2 \%$ of Res was released from the nanocarrier within $12 \mathrm{~h}$. The results demonstrate the spatiotemporally controllable release of Pt@Au-Ce6/Res-Lips under NIR laser stimulating condition. Subsequently, the morphologies of Pt@Au-Ce6/Res-Lips, which displayed the collapse of nanovesicles, were observed further after laser irradiation (Fig. S3). As the number of irradiations increased, the structure of the NPs loosened and gradually disintegrated. The results also illustrate the release of encapsulated drugs, and this finding was due to the hyperthermia-activated phase transition of liposome membrane from gel to liquid crystal structure and disintegratedPt@Au nanoshells. 

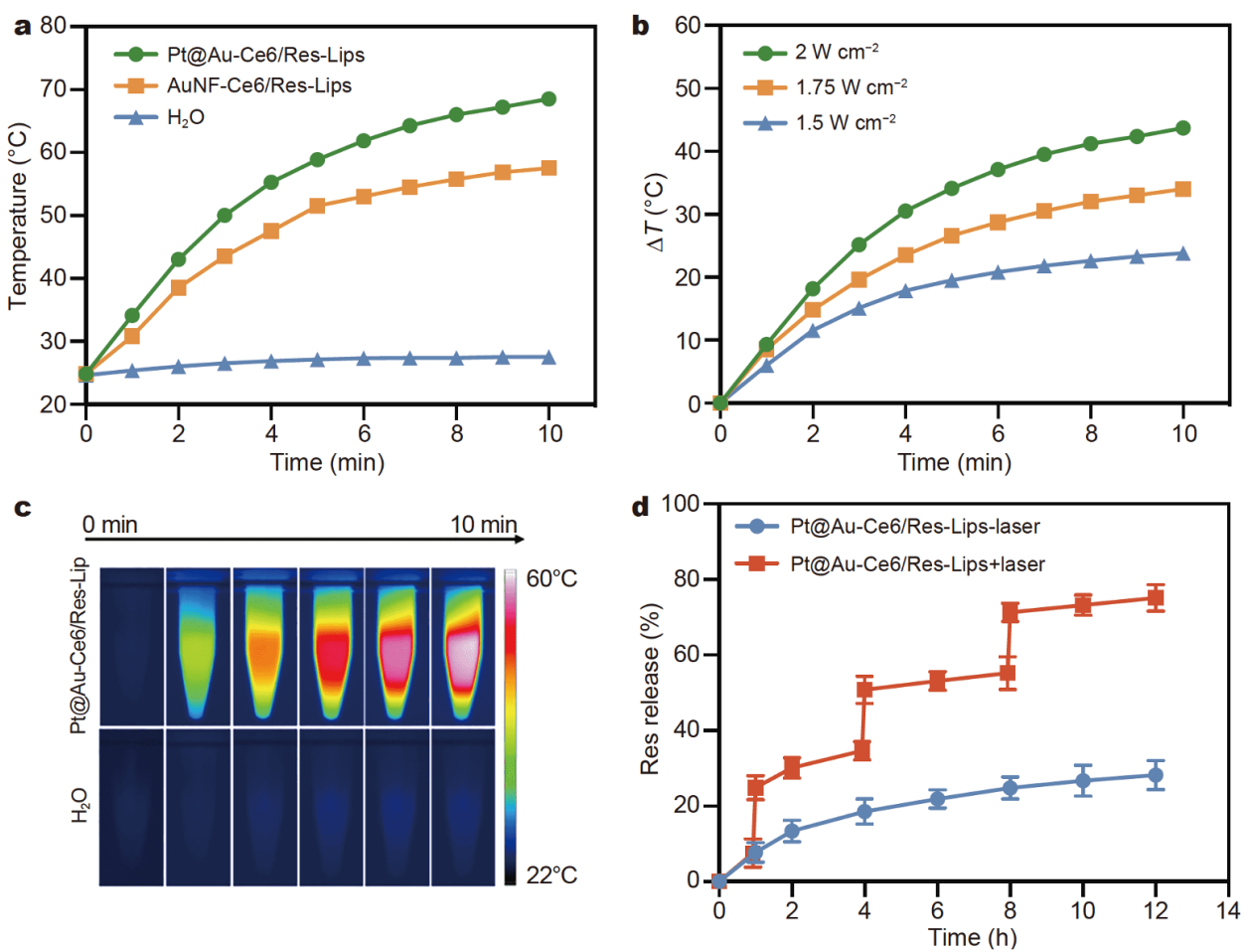

Figure 2 Photothermal effect measurement and controlled drug release. (a) Temperature profiles of Pt@Au-Ce6/Res-Lips, AuNF-Ce6/Res-Lips, and $\mathrm{H}_{2} \mathrm{O}$ under $808 \mathrm{~nm}$ laser irradiation $\left(2 \mathrm{~W} \mathrm{~cm}{ }^{-2}\right)$. (b) Temperature changes of Pt@Au-Ce6/Res-Lip solution under $808 \mathrm{~nm}$ laser irradiation with different power densities $\left(1.5,1.75\right.$, and $\left.2 \mathrm{~W} \mathrm{~cm}^{-2}\right)$. (c) Thermal images of Pt@Au-Ce6/Res-Lips and $\mathrm{H}_{2} \mathrm{O}$ irradiated with $808 \mathrm{~nm}$ laser $\left(1.5 \mathrm{~W}\right.$ cm ${ }^{-2}$ ) for $10 \mathrm{~min}$. (d) Res release from Pt@Au-Ce6/Res-Lips with $808 \mathrm{~nm}$ laser irradiation for $3 \mathrm{~min}$ at the designated time $(n=3)$.

\section{Catalytic activity of Pt@Au-Ce6/Res-Lips}

To evaluate the catalase activity of the sample, we used different concentrations of Pt@Au-Lips to catalyze commensurate $\mathrm{H}_{2} \mathrm{O}_{2}$ and monitored the process by using TMB as a chromophoric substrate for the peroxidase mimetic studies in the presence of $\mathrm{H}_{2} \mathrm{O}_{2}$. Oxygen acted as an electron donor in charge-transfer complexes derived from the one-electron oxidation of TMB under acidic condition, resulting in the solution color change from colorless to blue after being oxidized. The high absorbance at $652 \mathrm{~nm}$ corresponded to increased oxidation of TMB. In the experiment, with the increased concentrations of the catalyst, the blue color of the solution became prominent. Meanwhile, the characteristic absorption increased accordingly, which indicates that Pt@Au-Lips can effectively catalyze TMB oxidation with concentration independence (Fig. 3a). Subsequently, we measured the dissolved $\mathrm{O}_{2}$ generation of Pt@Au-Lips in the presence of $\mathrm{H}_{2} \mathrm{O}_{2}$ with the dissolved $\mathrm{O}_{2}$ meter. As displayed in Fig. 3b, the $\mathrm{O}_{2}$ production rates were positively related to the concentration of Pt. The corresponding photos shown in the inset reveal the increase in bubbles observed with the increased concentration of $\mathrm{Pt}$ at $5 \mathrm{~min}$. The above results indicate that the high concentration of catalytic NPs in TME favored the $\mathrm{O}_{2}$ generation, which can be promising to relieve hypoxia in the TME and improve the PDT efficacy significantly.

\section{Detection of reactive singlet oxygen}

Given the excellent catalytic property of the Pt@Au-Ce6/ Res-Lips, we explored their enhanced ROS generation behaviors associated with $\mathrm{Pt}$ catalyzing $\mathrm{H}_{2} \mathrm{O}_{2}$ decomposition. DPBF was used as a ROS probe to quantitatively analyze the generation manner of ROS. The decrease in DPBF absorbance showed the presence of ROS from Pt@Au-Ce6/Res-Lips, and it was trapped by DPBF [32]. As shown in Fig. 3c, the Pt@Au-Ce6/Res-Lips displayed a gradually decreasing absorbance at $410 \mathrm{~nm}$ along with the irradiation time of $660 \mathrm{~nm}$ laser $\left(0.15 \mathrm{~W} \mathrm{~cm}^{-2}\right)$. By contrast, no evident decrease was observed in AuNF-Ce6/ Res-Lips (Fig. 3d). The results directly prove that the Pt@Au-Ce6/Res-Lips can boost the peroxidase-like catalysis of $\mathrm{H}_{2} \mathrm{O}_{2}$ for the generation of considerable amounts of oxygen, leading to a significant improvement in the 

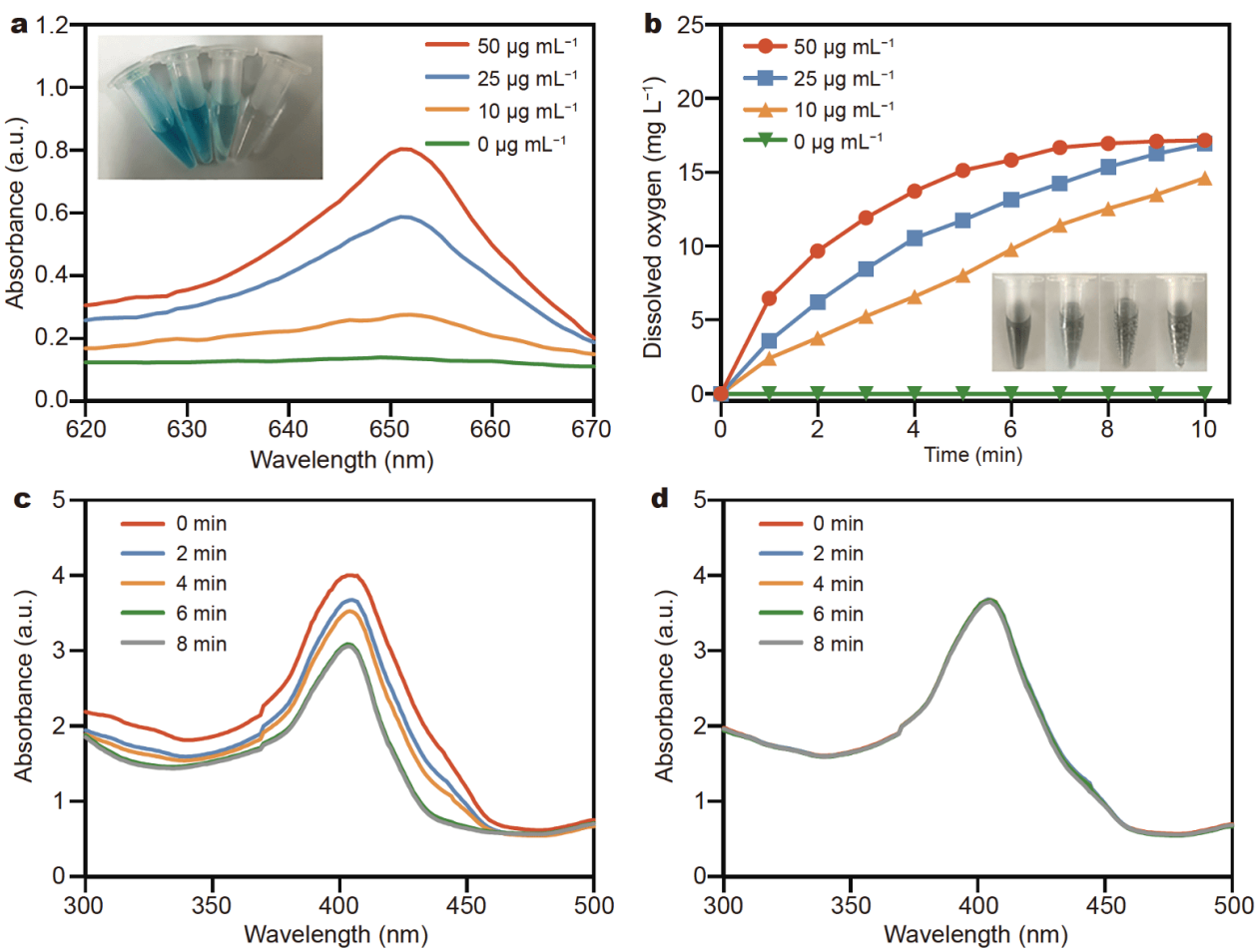

Figure 3 Catalase activity detection of Pt@Au-Ce6/Res-Lips. (a) Comparison of the absorbance evolution at 652 nm under different concentrations of Pt@Au-Lips after mixing with TMB for 5 min. The insets are the photographs of different concentrations of Pt@Au-Lips consisting of 0.1 mmol L ${ }^{-1}$ $\mathrm{H}_{2} \mathrm{O}_{2}$ and 1 mmol L ${ }^{-1}$ TMB. (b) Quantitative dissolved oxygen generation under different concentrations of Pt@Au-Ce6/Res-Lips after the reaction with $0.1 \mathrm{mmol} \mathrm{L} \mathrm{H}_{2} \mathrm{O}_{2}$. Time-course absorption spectra of DPBF solution with $0.1 \mathrm{mmol} \mathrm{L}{ }^{-1} \mathrm{H}_{2} \mathrm{O}_{2}$ treated with Pt@Au-Ce6/Res-Lips (c) and AuNFCe6/Res-Lips (d) under $660 \mathrm{~nm}$ laser irradiation $\left(0.15 \mathrm{~W} \mathrm{~cm}^{-2}\right)$.

ROS level.

A high concentration of ROS in the TME can oxidize $\mathrm{Pt}^{0}$ into $\mathrm{Pt}^{2+}$, which shows better penetration of nuclear membrane compared with PtNPs, to realize high cytotoxicity to tumor cells [33]. Hence, we measured the oxidization status changes of Pt before and after ROS generation in the simulated TME with an XPS system. As shown in Fig. S4, in the XPS spectra of Pt $4 \mathrm{f}$ (Fig. S4a), the peaks at binding energies of 71.34 and $74.89 \mathrm{eV}$ were assigned to $\mathrm{Pt}^{0}$, indicating that $\mathrm{Pt}$ was reduced to metallic PtNPs. After the Pt@Au-Ce6/Res-Lip solution was irradiated by $808 / 660 \mathrm{~nm}$ laser, the XPS spectra (Fig. S4b) can be deconvoluted into double pair of peaks at around $(70.84,74.19)$ and $(72.54,75.89) \mathrm{eV}$, which corresponded to $\left(\mathrm{Pt}^{0} 4 \mathrm{f}_{7 / 2}, \mathrm{Pt}^{0} 4 \mathrm{f}_{5 / 2}\right)$ and $\left(\mathrm{Pt}^{2+} 4 \mathrm{f}_{7 / 2}, \mathrm{Pt}^{2+} 4 \mathrm{f}_{5 / 2}\right)$, respectively, and thus confirmed the $\mathrm{Pt}^{2+}$ formation.

To verify the in vitro enhanced effect of PDT at the cellular level, we used DCFH-DA as an ROS probe to detect the intracellular ROS level by fluorescence microscopic observation, which was grounded on DCFH-DA which can be converted to DCF with green fluorescence in the presence of ROS [14]. Under the $660 \mathrm{~nm}$ laser irradiation, the Pt@Au-Ce6-Lips exhibited stronger green fluorescence than the AuNF-Ce6-Lips (Fig. 4a). Cancer cells prefer glycolysis and produce more $\mathrm{H}_{2} \mathrm{O}_{2}$ in tumor areas [2,7]. These results indicate that intracellular $\mathrm{H}_{2} \mathrm{O}_{2}$ can be converted into molecular oxygen through the catalysis of Pt and further react with Ce6 to produce a high concentration of ROS.

\section{Cellular uptake and in vitro combined antitumor therapy assay}

Cou6 with high fluorescence brightness was specifically selected as the Ce6 and Res substitute in this study to visualize the cellular uptake behaviors of Pt@Au-Cou6Lips in HeLa cells. As illustrated in Fig. 4b, Pt@Au-Cou6Lip treatment exhibited a visible green fluorescence in HeLa cells at $1 \mathrm{~h}$, confirming that Pt@Au-Cou6-Lips can be efficiently uptaken by tumor cells. Subsequently, the green fluorescence intensity increased over time and reached significant accumulation at $4 \mathrm{~h}$. The increase continued until the incubation time of $8 \mathrm{~h}$. Afterward, the fluorescence intensity showed no evident changes compared with that at $4 \mathrm{~h}$, indicating that the internalization 

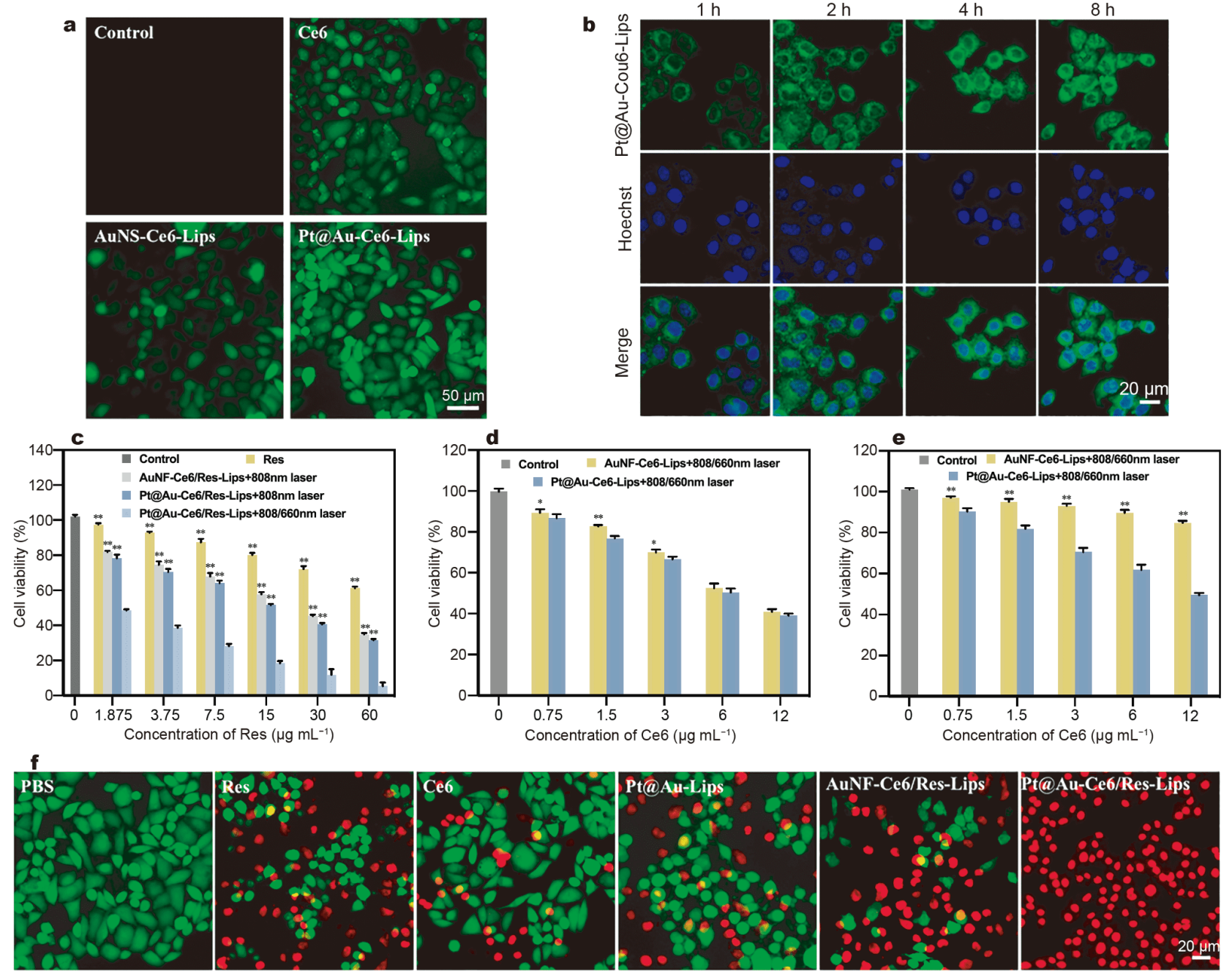

Figure 4 Cell uptake and in vitro antitumor assay. (a) Fluorescence images of DCFH-DA-stained HeLa cells (added with $0.1 \mathrm{mmol} \mathrm{L}^{-1} \mathrm{H}_{2} \mathrm{O}_{2}$ ) treated with PBS, Pt@Au-Lips, AuNF-Ce6-Lips, and Pt@Au-Ce6-Lips under $660 \mathrm{~nm}$ laser irradiation $\left(0.15 \mathrm{~W} \mathrm{~cm}^{-2}\right)$. (b) Cellular internalization of Pt@AuCou6-Lips at 1, 2, 4, and $8 \mathrm{~h}$. (c) Cell viabilities of Hela cells treated with different formulations at various concentrations of Res (mean \pm SD, $n=3$; **P< 0.01 compared with Pt@Au-Ce6/Res-Lips + 808/660 nm laser group). Cell viabilities of Hela cells treated with AuNF-Ce6-Lips and Pt@Au-Ce6Lips under normoxic (d) or hypoxic (e) condition (mean $\pm \mathrm{SD}, n=3$; ${ }^{*} P<0.05$, ${ }^{* *} P<0.01$ compared with Pt@Au-Ce6/Res-Lips + 808/660 nm laser group). (f) Fluorescence images of HeLa cells co-stained with FDA (live cells, green) and PI (dead cells, red) treated with different formulations: PBS, Res, Ce6 with 660 nm laser, Pt@Au-Lips with 808 nm laser, AuNF-Ce6/Res with 808/660 nm laser, and Pt@Au-Ce6/Res-Lips with 808/660 nm laser.

of Pt@Au-Cou6-Lips reached the maximum. Moreover, the quantitative FCM analysis showed similar outcomes, implying that the internalization of Pt@Au-Cou6-Lips reached a plateau at $4 \mathrm{~h}$ (Fig. S5).

Different formulations containing various concentrations of Res were incubated with HeLa cells to evaluate the antitumor effect of Pt@Au-Ce6/Res-Lips. All the Resloaded formulations displayed a dose-dependent toxicity to HeLa cells (Fig. 4c). Under the $808 \mathrm{~nm}$ laser irradiation, the AuNF-Ce6/Res-Lips group revealed a 39\% cell viability at a Res concentration of $60 \mu \mathrm{g} \mathrm{mL}^{-1}$, which was remarkably lower than that of the Res-treated group. Similarly, in Pt@Au-Ce6/Res-Lips, more than 37\% cells remained alive under the $808 \mathrm{~nm}$ laser irradiation. Given that hyperthermia can further enhance tumor cell uptake for NPs and accelerate the catalytic decomposition of $\mathrm{H}_{2} \mathrm{O}_{2}$ by Pt@Au-Ce6/Res-Lips, more $\mathrm{O}_{2}$ were generated, and the cell cytotoxicity derived from Pt@Au-Ce6/ResLips sharply increased after successive irradiation by the $808 / 660 \mathrm{~nm}$ laser. With the multi-action from chemotherapeutic drug, hyperthermia, and ROS, the Pt@AuCe6/Res-Lips had a considerably high potency to destroy 
HeLa cells at all the tested concentrations.

The heterogeneous tumor cell growth and dysfunctional vasculature result in a high concentration of $\mathrm{H}_{2} \mathrm{O}_{2}$ and hypoxia in TME [34]. Hence, the PDT efficiencies of Pt@Au-Ce6-Lips and AuNF-Ce6-Lips incubated with HeLa cells in either $\mathrm{O}_{2}$-deficient or $\mathrm{O}_{2}$-sufficient conditions were examined. The phototoxicity of the NPs increased along with the concentration of photosensitizer Ce6 (Fig. 4d and e). Under normoxic condition, the Pt@Au-Ce6-Lips displayed a similar PDT effect with the AuNF-Ce6-Lips, with a cell viability of $43 \%$ at a Ce6 concentration of $12 \mu \mathrm{gL}^{-1}$. With the inadequate $\mathrm{O}_{2}$ supply, the phototoxicity of AuNF-Ce6-Lips was significantly reduced, confirming that the treatment effect of Ce6 greatly declined in the case of hypoxia. As the Pt@Au-Ce6-Lips can decompose the abundant $\mathrm{H}_{2} \mathrm{O}_{2}$ in TME to generate $\mathrm{O}_{2}$, the additional triplet ground-state molecular oxygen $\left({ }^{3} \mathrm{O}_{2}\right)$ was transformed into its highly reactive singlet oxygen $\left({ }^{1} \mathrm{O}_{2}\right)$ analog [7]. With the resulting ROS inducing cell apoptosis or necrosis [35], the cell viability of Pt@Au-Ce6-Lips distinctly demonstrated a higher cytotoxicity under hypoxic condition compared with AuNF-Ce6-Lips. Similar results have been observed in the comparison of the PDT capabilities of Pt@Au-Ce6Lips and free Ce6 (Fig. S6). Under normoxic environment, the free Ce6 and nanodrug showed similar PDT effects. With the increase in Ce6 concentration, the cell viability of the two groups decreased without significant difference. In the hypoxic environment, the photodynamic effect of Ce6 was limited, whereas the nanodrug still showed a good photodynamic effect. With the increase in Ce6 concentration, the difference in cell viability between Ce6 and Pt@Au-Ce6-Lips increased. The prepared hypoxia-relieving nanodrug achieved excellent photodynamic therapeutic effect and cytotoxicity in the hypoxic environment.

Fluorescence staining of live/dead cells was performed to further intuitively observe the above results, and the findings are presented in Fig. 4f. Free Res, Ce6, and Pt@Au-Lips, regardless of laser irradiation, presented vast green fluorescence, implying that monotherapy had low cytotoxicity to tumor cells. Most of the cells exhibited red fluorescence in the group treated with AuNF-Ce6/ResLips followed by $808 / 660 \mathrm{~nm}$ laser irradiation, indicating that the combination of tripartite treatments can kill most tumor cells. The strongest red fluorescence was observed in the cells treated with Pt@Au-Ce6/Res-Lips and irradiated successively by 808 and $660 \mathrm{~nm}$ laser. Given that $\mathrm{H}_{2} \mathrm{O}_{2}$ can be effectively decomposed by Pt@Au-Res/Ce6Lips to generate $\mathrm{O}_{2}$, the antitumor effect was greatly en- hanced.

\section{In vivo cancer therapeutic efficacy and biosafety assay}

To demonstrate the photothermal capacity of Pt@AuCe6/Res-lips in tumors, we monitored the temperature changes of tumor-bearing mice intravenously injected with Pt@Au-Ce6/Res-Lips using an IR thermal imaging camera. Significant thermal signals were observed for the group treated with Pt@Au-Ce6/Res-Lips and 808 nm laser irradiation (Fig. 5a). As shown in Fig. 5b, the tumor surface temperature rapidly increased to $54^{\circ} \mathrm{C}$ for $4 \mathrm{~min}$, which adequately ablated the tumor cells and had insignificant side effects on wound tissue in vivo. By contrast, nearly no remarkable tumor signals were observed in the saline group. The results were consistent with the solution data in vitro, indicating that Pt@Au-Ce6/Res-Lips are ideal candidates for effective PTT.

We further evaluated the in vivo antitumor effect of Pt@Au-Ce6/Res-Lips. In this study, different formulations were injected into tumor-bearing mice through intratumoral administration. Under the various treatments, the tumor volumes were monitored during the subsequent 15 days. The tumors in the saline group grew remarkably during the therapy, exhibiting a 12 -fold increment (Fig. 5c-e). The groups treated with free Res and free Ce6 plus 660 nm laser irradiation or Pt@Au-Lips plus $808 \mathrm{~nm}$ laser irradiation showed partial tumor suppression behavior in 15 days. Comparatively, the Pt@Au-Ce6Lips and AuNF-Ce6-Lips with $808 \mathrm{~nm} / 660 \mathrm{~nm}$ laser irradiation groups induced noticeable tumor growth inhibition. As PtNPs can ameliorate tumor hypoxia by decomposing $\mathrm{H}_{2} \mathrm{O}_{2}$ to produce $\mathrm{O}_{2}$ in TMEs, the inhibition rate of Pt@Au-Ce6-Lips group was higher than that of AuNF-Ce6-Lips, indicating the enhanced PDT effect. Another possible reason might be the high concentration of ROS, which can oxidize $\mathrm{Pt}^{0}$ into $\mathrm{Pt}^{2+}$, which showed better penetration of nuclear membrane compared with PtNPs, in the TME to realize high cytotoxicity to tumor cells $[30,33]$. Based on the above results, significant suppression effects can be observed in the Pt@Au-Ce6/ResLips $+808 / 660 \mathrm{~nm}$ laser group, and the tumor inhibition rate was as high as $92 \%$ with the combination of interlocking trimodal therapeutic options. Meanwhile, no evident abnormal body weight changes were observed between different groups, further manifesting the high therapeutic biosecurity of the nanocarriers. Fig. 5h presents the H\&E staining of primary organs and tumor tissue of the saline and Pt@Au-Ce6/Res-Lips + $808 / 660 \mathrm{~nm}$ laser groups. Compared with the saline group, the primary organs in the nanodrug group showed 
a

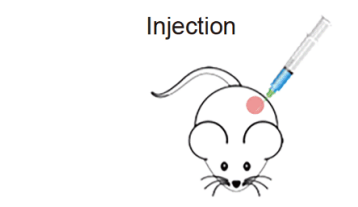

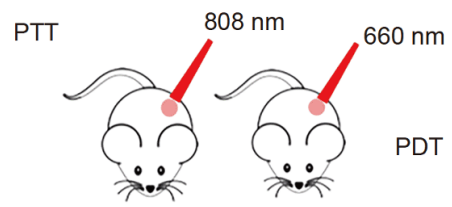

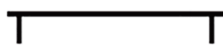

1 day
$4 \mathrm{~h}$
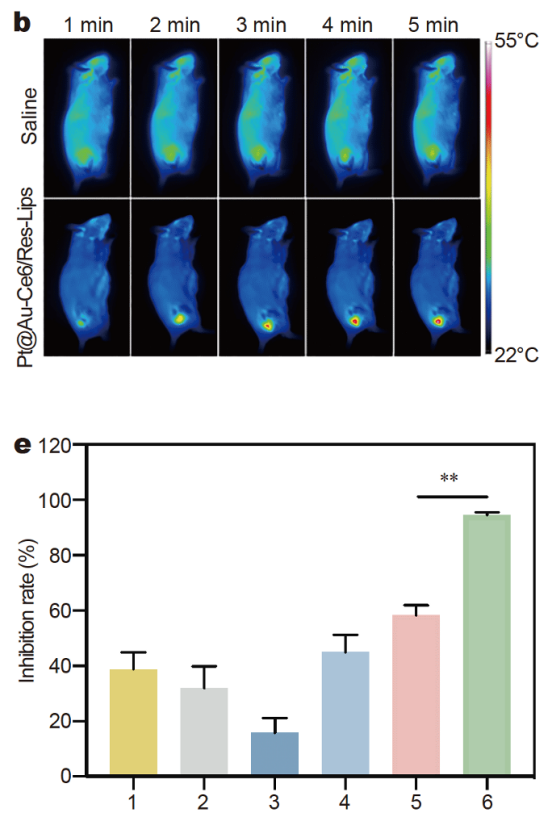

h
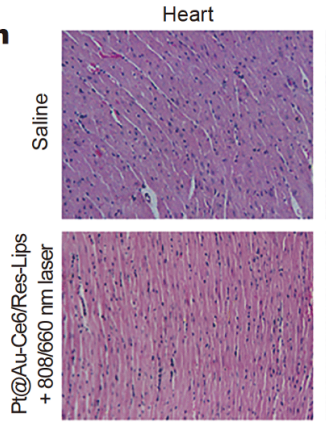

Liver
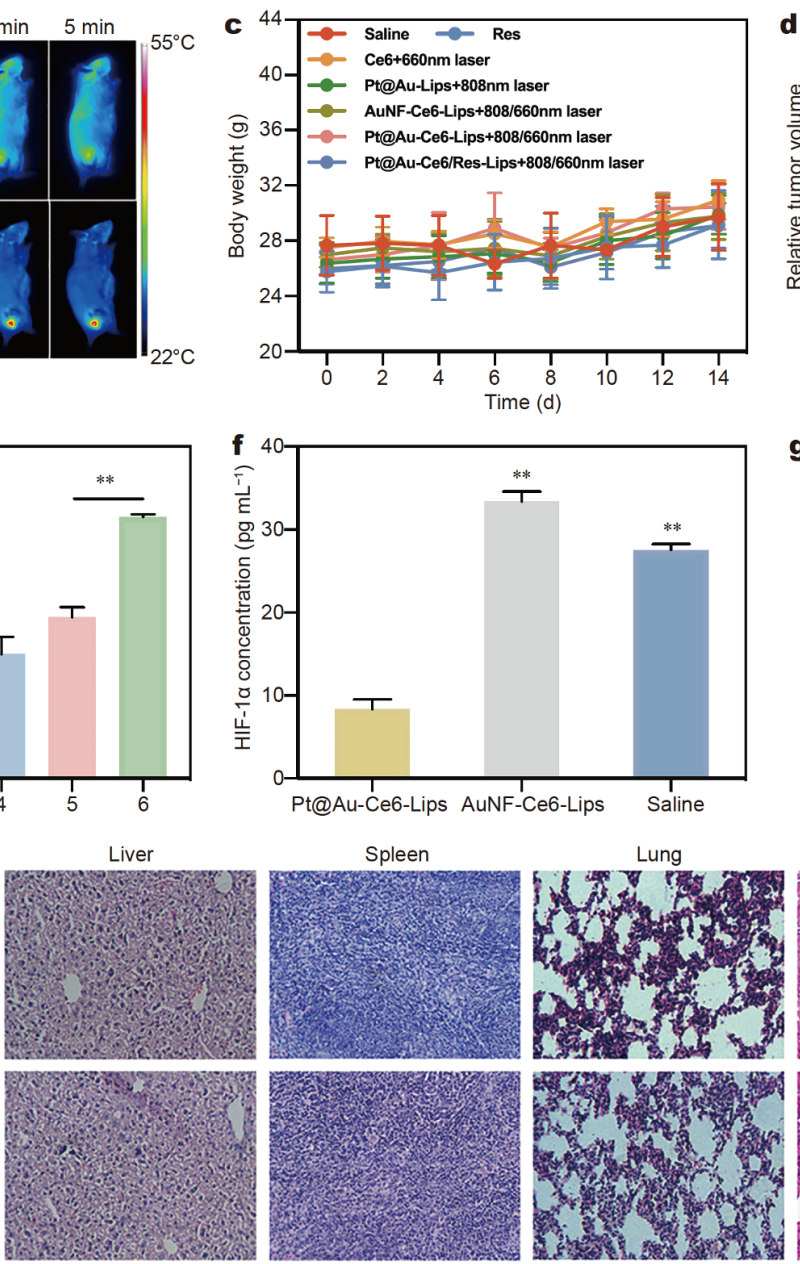
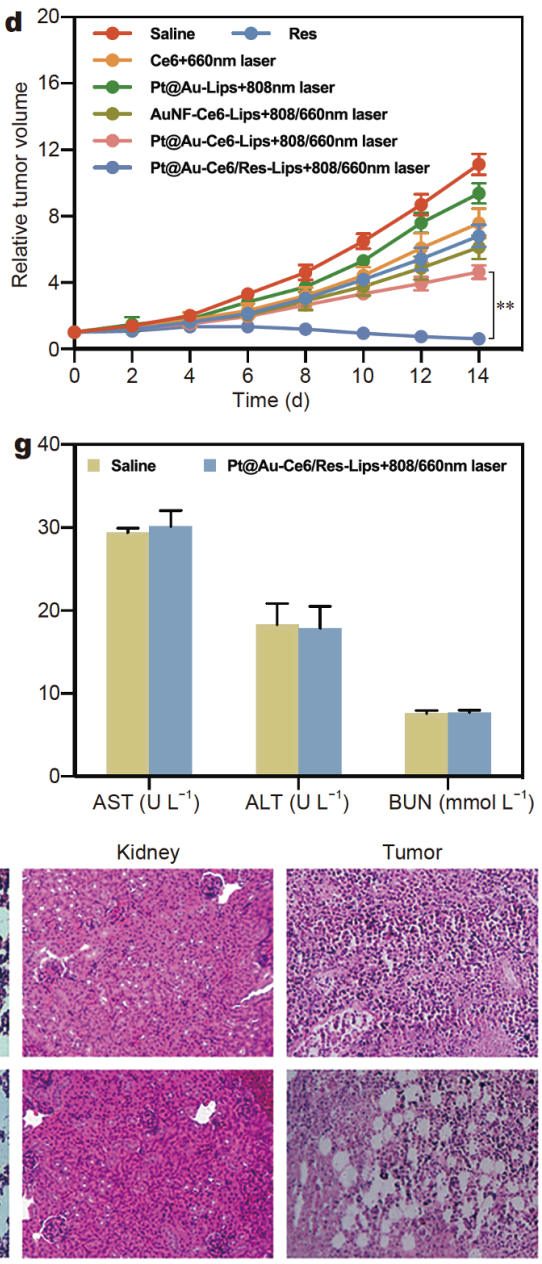

Figure 5 In vivo antitumor effect. (a) Schematic of the timeline for in vivo treatment. (b) IR thermal images of U14 tumor-bearing mice after $808 \mathrm{~nm}$ laser irradiation. (c) Body weight changes of U14 tumor-bearing mice subjected to different treatments $(n=6)$. (d) Relative tumor growth curves of different groups subjected to different treatments (mean $\pm \mathrm{SD}, n=6$; ** $P<0.01$ compared with Pt@Au-Ce6/Res-Lips + 808/660 nm laser group). (e) Inhibition rates of different treatments. Group 1: Res; Group 2: Ce6; Group 3: Pt@Au-Lips + 808 nm; Group 4: AuNF-Ce6-Lips + 808/660 nm; Group 5: Pt@Au-Ce6-Lips + 808/660 nm; Group 6: Pt@Au-Ce6/Res-Lips + 808/660 nm. (mean \pm SD, $n=6$; **P<0.01 compared with Pt@Au-Ce6/ Res-Lips + 808/660 nm laser group). (f) HIF-1a of U14 tumor-bearing mice treated with saline, AuNF-Ce6-Lips, and Pt@Au-Ce6-Lips upon 808/ $660 \mathrm{~nm}$ laser irradiation (mean $\pm \mathrm{SD}, n=3$; **P $<0.01$ compared with Pt@Au-Ce6/Res-Lips group). (g) Serum levels of AST, ALT, and BUN in U14 tumor-bearing mice treated with saline and Pt@Au-Ce6/Res-Lips + 808/660 nm laser $(n=3)$. (h) Histological examination of primary organs and tumor tissue of the saline and Pt@Au-Ce6/Res-Lips groups. Sections for light microscopy were stained with H\&E. Magnification was 200×.

no evident pathological changes. However, significant cell necrosis and tissue damage can be observed in the tumor tissue of the nanodrug group. Overall, Pt@Au-Ce6/Res-
Lips $+808 / 660 \mathrm{~nm}$ laser demonstrated excellent antitumor effects with biological safety.

Given that tumor hypoxia relief will efficiently enhance 
the PDT effect, the HIF-1 $a$ expression level was examined by HIF-1 $\alpha$ assay kit to analyze hypoxia in the tumor sites treated with Pt@Au-Ce6-Lips and AuNF-Ce6-Lips. HIF$1 \alpha$ is a vital regulator of the transcriptional response to acute and chronic hypoxia [14]. As shown in Fig. 5f, the HIF-1 $\alpha$ concentration of the Pt@Au-Ce6-Lip group $\left(8.335 \mathrm{pg} \mathrm{mL}^{-1}\right)$ was reduced by almost five times compared with that of the AuNF-Ce6-Lip group without Pt (33.378 $\mathrm{pg} \mathrm{mL}^{-1}$ ) and lower than that of the saline group (27.548 $\mathrm{pg} \mathrm{mL}^{-1}$ ), indicating that PtNPs can ameliorate tumor hypoxia by decomposing $\mathrm{H}_{2} \mathrm{O}_{2}$ to produce $\mathrm{O}_{2}$ in TME containing abundant $\mathrm{H}_{2} \mathrm{O}_{2}$, leading to the reduction of HIF-1a. With the decrease in HIF-1a, the therapeutic efficacy of the PDT with Ce6 was improved.

The expressions of other four hypoxia target genes, such as VEGF, EPO, GLUT3 and MDR1, were detected to further certify the hypoxia relief. VEGF is a pivotal regulator of physiological and pathological angiogenesis. In hypoxic tumor tissues, VEGF can promote neovascularization by activating the differentiation and proliferation of vascular endothelial cells, thereby increasing hypoxic blood flow and oxygen supply to accommodate hypoxia. EPO is essential for erythropoiesis to transport oxygen in blood. Under hypoxic conditions, tumor cells can increase the expression of EPO by increasing the transcription of EPO gene, consequently forming more red blood cells and promoting the delivery of oxygen. GLUT3 is one of the glucose transporters on the cytomembrane. Influenced by the tumor hypoxic environment, oxidative phosphorylation in cells is inhibited, and tumor cells promote glycolysis to meet the energy metabolism of the body, which induces the increased expression level of GLUT3. MDR1 is closely related to drug resistance. The transcriptional activity of MDR1 improves under hypoxic conditions, which results in the non-sensitivity of CHT. As shown in Fig. S7, the levels of VEGF, EPO, GLUT3, and MDR1 in Pt@Au-Ce6/Res-Lips + 808/660 nm laser groups significantly decreased compared with those in the saline group. The biological effects induced by hypoxia, such as neovascularization, erythropoiesis, repressed oxidative phosphorylation, and multidrug resistance, improved after the treatment by Pt@Au-Ce6/Res-Lips, and they were used to identify the tumor hypoxia relief.

Finally, the biosafety of Pt@Au-Ce6/Res-Lips in vivo was investigated by biochemical indexes, including ALT, AST, and BUN. ALT and AST are hepatic markers; the injury of liver leads to significantly increased levels of ALT and AST. BUN is a main parameter for detecting kidney function. When the kidneys are damaged, urea nitrogen from the blood is difficult to remove by the glomerular, which causes a high level of BUN [36]. As shown in Fig. 5g, the ALT, AST, and BUN of Pt@Au-Ce6/ Res-Lips group in general had no significant changes compared with those of the healthy mice, indicating the Pt@Au-Ce6/Res-Lips had no evident toxicity to the mice at the given dose.

\section{CONCLUSION}

In summary, we successfully designed a novel nanotherapeutic nanocarrier (Pt@Au-Ce6/Res-Lips) that can regulate tumor hypoxia to enhance the PDT effect. In the nanovesicle, Pt with good catalase-like activity can decompose endogenous $\mathrm{H}_{2} \mathrm{O}_{2}$ to produce vast $\mathrm{O}_{2}$ to ameliorate tumor hypoxia. Meanwhile, the Pt@Au nanoshells with excellent photothermal effect can induce hyperthermia under $808 \mathrm{~nm}$ laser irradiation to release Ce6 and Res controllably, ablate the tumor cells, and accelerate the uptake of nanocarriers. Furthermore, the photosensitizer Ce6 under $660 \mathrm{~nm}$ laser irradiation can convert energy to produce ROS, which can efficiently induce the apoptosis and necrosis of tumor cells and oxidize $\mathrm{Pt}^{0}$ into $\mathrm{Pt}^{2+}$, thus realizing the high cytotoxicity to tumor cells. With the action of drugs, hyperthermia, and ROS, the Pt@Au-Ce6/Res-Lips exhibited a substantially high potency for destroying tumor cells through interlocking trimodal therapeutic options, indicating their great potential to be used as effective multifunctional agents for cancer therapy.

Received 6 May 2020; accepted 14 August 2020; published online 11 November 2020

$1 \mathrm{Wu}$ W, Shao X, Zhao J, et al. Controllable photodynamic therapy implemented by regulating singlet oxygen efficiency. Adv Sci, 2017, 4: 1700113

$2 \mathrm{Yu} \mathrm{W}$, Liu $\mathrm{T}$, Zhang $\mathrm{M}$, et al. $\mathrm{O}_{2}$ economizer for inhibiting cell respiration to combat the hypoxia obstacle in tumor treatments. ACS Nano, 2019, 13: acsnano.8b07852

3 Zhang K, Zhang Y, Meng X, et al. Light-triggered theranostic liposomes for tumor diagnosis and combined photodynamic and hypoxia-activated prodrug therapy. Biomaterials, 2018, 185: 301309

4 Zhang Y, Wang F, Liu C, et al. Nanozyme decorated metal-organic frameworks for enhanced photodynamic therapy. ACS Nano, 2018, 12: 651-661

5 Song X, Feng L, Liang C, et al. Liposomes co-loaded with metformin and chlorin e6 modulate tumor hypoxia during enhanced photodynamic therapy. Nano Res, 2016, 10: 1200-1212

6 Yu Z, Zhou P, Pan W, et al. A biomimetic nanoreactor for synergistic chemiexcited photodynamic therapy and starvation therapy against tumor metastasis. Nat Commun, 2018, 9: 5044

7 Li X, Kwon N, Guo T, et al. Innovative strategies for hypoxictumor photodynamic therapy. Angew Chem Int Ed, 2018, 57: 11522-11531 
8 Li M, Xia J, Tian R, et al. Near-infrared light-initiated molecular superoxide radical generator: Rejuvenating photodynamic therapy against hypoxic tumors. J Am Chem Soc, 2018, 140: 14851-14859

9 Song G, Liang C, Yi X, et al. Perfluorocarbon-loaded hollow $\mathrm{Bi}_{2} \mathrm{Se}_{3}$ nanoparticles for timely supply of oxygen under near-infrared light to enhance the radiotherapy of cancer. Adv Mater, 2016, 28: 27162723

10 Luo Z, Zheng M, Zhao P, et al. Self-monitoring artificial red cells with sufficient oxygen supply for enhanced photodynamic therapy. Sci Rep, 2016, 6: 23393

11 Tang W, Zhen Z, Wang M, et al. Red blood cell-facilitated photodynamic therapy for cancer treatment. Adv Funct Mater, 2016, 26: $1757-1768$

12 Fan Y, Zhou T, Cui P, et al. Modulation of intracellular oxygen pressure by dual-drug nanoparticles to enhance photodynamic therapy. Adv Funct Mater, 2019, 29: 1806708

13 Yang ZL, Tian W, Wang Q, et al. Oxygen-evolving mesoporous organosilica coated prussian blue nanoplatform for highly efficient photodynamic therapy of tumors. Adv Sci, 2018, 5: 1700847

14 Zhu P, Chen Y, Shi J. Nanoenzyme-augmented cancer sonodynamic therapy by catalytic tumor oxygenation. ACS Nano, 2018, 12: $3780-3795$

15 Ouyang J, Wang L, Chen W, et al. Biomimetic nanothylakoids for efficient imaging-guided photodynamic therapy for cancer. Chem Commun, 2018, 54: 3468-3471

16 Wang $\mathrm{H}$, Chao Y, Liu J, et al. Photosensitizer-crosslinked in-situ polymerization on catalase for tumor hypoxia modulation \& enhanced photodynamic therapy. Biomaterials, 2018, 181: 310-317

17 Zou MZ, Liu WL, Li CX, et al. A multifunctional biomimetic nanoplatform for relieving hypoxia to enhance chemotherapy and inhibit the pd-1/pd-11 axis. Small, 2018, 14: 1801120

18 Li J, Xie C, Huang J, et al. Semiconducting polymer nanoenzymes with photothermic activity for enhanced cancer therapy. Angew Chem Int Ed, 2018, 57: 3995-3998

19 Hsieh CT, Tzou DY, Jiang MT. Methanol electro-oxidation on Pt nanocatalysts prepared by atomic layer deposition. J Electroanal Chem, 2017, 794: 139-147

20 Baronia R, Goel J, Tiwari S, et al. Efficient electro-oxidation of methanol using PtCo nanocatalysts supported reduced graphene oxide matrix as anode for DMFC. Int J Hydrogen Energy, 2017, 42: 10238-10247

21 Gao Z, Xu M, Lu M, et al. Urchin-like (gold core)@(platinum shell) nanohybrids: A highly efficient peroxidase-mimetic system for in situ amplified colorimetric immunoassay. Biosens Bioelectron, 2015, 70: 194-201

22 Liu Y, Wu H, Li M, et al. $\mathrm{pH}$ dependent catalytic activities of platinum nanoparticles with respect to the decomposition of hydrogen peroxide and scavenging of superoxide and singlet oxygen. Nanoscale, 2014, 6: 11904-11910

23 Luo H, Wang Q, Deng Y, et al. Mutually synergistic nanoparticles for effective thermo-molecularly targeted therapy. Adv Funct Mater, 2017, 27: 1702834

24 Chen Z, Thiramanas R, Schwendy M, et al. Upconversion nanocarriers encapsulated with photoactivatable ru complexes for nearinfrared light-regulated enzyme activity. Small, 2017, 13: 1700997

25 Zhang D, Qin X, Wu T, et al. Extracellular vesicles based selfgrown gold nanopopcorn for combinatorial chemo-photothermal therapy. Biomaterials, 2019, 197: 220-228

26 Li L, Fu Y, Xu Z, et al. Seedless synthetic branched gold nanoshells for chemo-thermal antitumor therapy. J Mater Chem B, 2020, 8: 5155-5166

27 Wang M, Liu Y, Zhang X, et al. Gold nanoshell coated thermo-pH dual responsive liposomes for resveratrol delivery and chemophotothermal synergistic cancer therapy. J Mater Chem B, 2017, 5: 2161-2171

28 Luo L, Bian Y, Liu Y, et al. Combined near infrared photothermal therapy and chemotherapy using gold nanoshells coated liposomes to enhance antitumor effect. Small, 2016, 12: 4103-4112

29 Li L, Liu H, Bian J, et al. Ag/Pd bimetal nanozyme with enhanced catalytic and photothermal effects for ROS/hyperthermia/chemotherapy triple-modality antitumor therapy. Chem Eng J, 2020, 397: 125438

30 Luo L, He H, Li C, et al. Near-infrared responsive bimetallic nanovesicles for enhanced synergistic chemophotothermal therapy. ACS Biomater Sci Eng, 2019, 5: 1321-1331

31 Liu Y, Shu G, Li X, et al. Human HSP70 promoter-based Prussian blue nanotheranostics for thermo-controlled gene therapy and synergistic photothermal ablation. Adv Funct Mater, 2018, 28: 1802026

32 Li Y, Liu Z, Hou Y, et al. Multifunctional nanoplatform based on black phosphorus quantum dots for bioimaging and photodynamic/photothermal synergistic cancer therapy. ACS Appl Mater Interfaces, 2017, 9: 25098-25106

33 Shoshan MS, Vonderach T, Hattendorf B, et al. Peptide-coated platinum nanoparticles with selective toxicity against liver cancer cells. Angew Chem Int Ed, 2019, 58: 4901-4905

34 Wei J, Li J, Sun D, et al. A novel theranostic nanoplatform based on Pd@Pt-PEG-Ce6 for enhanced photodynamic therapy by modulating tumor hypoxia microenvironment. Adv Funct Mater, 2018, 28: 1706310

35 Wang $\mathrm{Y}$, Huang $\mathrm{X}$, Tang $\mathrm{Y}$, et al. A light-induced nitric oxide controllable release nano-platform based on diketopyrrolopyrrole derivatives for ph-responsive photodynamic/photothermal synergistic cancer therapy. Chem Sci, 2018, 9: 8103-8109

36 Bian K, Zhang X, Liu K, et al. Peptide-directed hierarchical mineralized silver nanocages for anti-tumor photothermal therapy. ACS Sustain Chem Eng, 2018, 6: 7574-7588

Acknowledgements This work was financially supported by the National Natural Science Foundation (21776238, 21476190, and 31801198), and Hebei province Natural fund key projects (B2019203479).

Author contributions Luo L designed and engineered the samples; Luo L characterized the samples with support from Cong C; Luo L and Li L performed the experiments; He Y performed the data analysis; Hao $\mathrm{Z}$ contributed to the theoretical analysis; Luo $\mathrm{L}$ wrote the paper with support from Li L; Li L revised the paper and supplemented experiments with the help of Luo L. All authors contributed to the general discussion.

Conflict of interest The authors declare that they have no conflict of interest.

Supplementary information Details of the experimental materials and characterization procedures are available in the online version of the paper. 


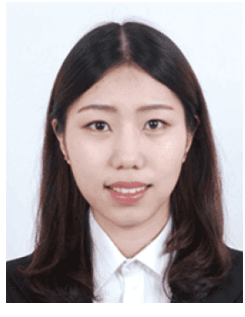

Liyao Luo received her $\mathrm{PhD}$ degree from Yanshan University in 2019. She is currently engaged in related work in the pharmaceutical field.

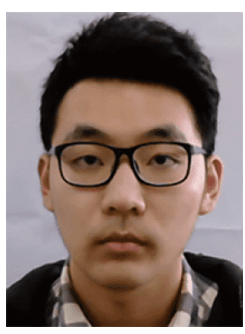

Lei Li is currently a PhD student in Prof. Dawei Gao's group at Yanshan University. His main research focuses on the syntheses of noble metal nanomaterials and their applications for antitumor treatment.

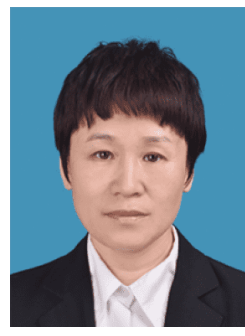

Dawei Gao is currently a full professor at Yanshan University. Her research interests include the syntheses of nanomaterials and their bioapplications.
类过氧化氢酶纳米系统缓解缺氧用于联锁三重态 癌症治疗

骆丽圭 ${ }^{\dagger}$, 李否 ${ }^{\dagger}$, 丛聪, 赫雅倩, 郝紫泞, 高大威 ${ }^{*}$

摘要 缺氧作为实体瘤的标志, 严重地影响了整体抗肿瘤治疗效 果, 尤其是光动力疗法. 在本文中, 我们开发了具有近红外光响应 性的类过氧化氢酶纳米囊泡: 铂/金纳米壳包覆的二氢卟酚 $\mathrm{e} 6$ (Ce6)/白㯟芦醇(Res)脂质体(Pt@Au-Ce6/Res-Lips), 以解决这一棘 手的问题. Pt@Au-Ce6/Res-Lips可以分解肿瘤微环境中过表达的过 氧化氢, 从而产生大量氧气, 以增强光动力疗法的效果. 在 $808 \mathrm{~nm}$ 激光照射下, 金纳米壳在病变部位产生高热, 以消融肿瘤细胞, 同时 可控地诱导光敏剂Ce6和化疗药物Res的释放. 此外, 在 $660 \mathrm{~nm}$ 激光 的刺激下, 形成了大量的活性氧(ROS) 以诱导肿瘤细胞的调亡和坏 死. 随着三重态治疗模式(化疗、光热治疗和光动力治疗)的级联, Pt@Au-Ce6/Res-Lips在体外和体内研究中均显示出超高的肿瘤抑 制率, 这标志着Pt@Au-Ce6/Res-Lips纳米囊泡将有望成为高效的肿 瘤治疗药物. 